\title{
Does Public Transport Accessibility Enhance Subjective Well-being? A study of the City of Johannesburg
}

\author{
Nahungu Lionjanga ${ }^{a},{ }^{*}$ and Christo Venter ${ }^{b}$ \\ a Department of Civil Engineering, University of Pretoria, Private Bag X20, Hatfield, 0028, South Africa \\ ${ }^{b}$ Department of Civil Engineering and Centre for Transport Development, University of Pretoria, Private Bag X20, \\ Hatfield, 0028, South Africa \\ ${ }^{*}$ Corresponding author. \\ E-mail addresses: nahungu.lionjanga@up.ac.za (N. Lionjanga), christo.venter@up.ac.za (C. Venter).
}

\section{Keywords:}

Accessibility; Time-series analysis; Well-being; Quality of Life; Johannesburg, Public transport; Bus Rapid Transit

\section{ABSTRACT}

Within the corpus of accessibility measures is the Net Wage After Commute, which describes the potential wage earnable less the transport costs incurred to commute to work from a particular location. This paper explores the time-series development of accessibility, using this poverty-relevant metric, in low-income residential areas of the City of Johannesburg, biennially from 2009 to 2013 when accessibility patterns were altered as a result of major investment in the Bus Rapid Transit (BRT) system. The results suggest that significant changes in accessibility are driven by improved affordability rather than spatial coverage enhancements, which were very marginal in the case of Johannesburg. A difference-indifferences approach is adopted to explore the effects of access to the BRT on the subjective well-being of lower-income households. The model fails to find evidence that the additional accessibility provided by the BRT improves the general sense of well-being in the communities it serves. We hypothesise that the incremental accessibility improvement is so small as to be overwhelmed by other social drivers of well-being. We do find evidence however of well-being improvements among the narrower cohort of actual users of BRT, especially in terms of their satisfaction with the amount of free time they have. This suggests that the BRT in Johannesburg is beneficial as a transport project, but not yet as a general urban intervention able to leverage wider improvements in life satisfaction within served communities.

\section{Introduction and background}

Transport and planning policy is prioritising the improvement of transport accessibility and equity across various regions in the world; it is no different in the Gauteng province (GPG, 2012; CoJ, 2013). Located in the polycentric province is the City of Johannesburg (CoJ) which is South Africa's largest and most dynamic economy (Todes, 2012). However, despite its economic success, the CoJ grapples with relatively high levels of poverty, unemployment and inequality (Todes, 2012; CoJ, 2013). During the apartheid era, non-white groups were relocated to residential areas which are predominantly located in the peripheries of the CoJ (Todes, 2012). This resulted in low-income groups residing in areas that were politically excluded from receiving adequate funding, therefore, these residents suffered from poor infrastructure and service delivery (Todes, 2012).

The Reconstruction and Development Programme (RDP) was introduced in 1994 as a poverty alleviation strategy which involved, amongst other things, providing housing to the urban poor. However, RDP housing continues to be developed within or close to these lowincome residential areas due to escalating land prices in the city centre (Todes, 2012; CoJ, 
2013), perpetuating the spatial exclusion and the financial and travel time burden experienced by low-income groups. To combat this historic spatial exclusion, the CoJ introduced the "Corridors of Freedom" as an initiative to drive spatial integration through land-use and transport interventions (Venter, 2016). The first of these corridors of freedom was introduced during the study period $(2009-2013)$ through the introduction of the Bus Rapid Transit (BRT) system dubbed Rea Vaya (CoJ, 2013; Gotz et al., 2014). The Rea Vaya Phase 1A corridor operates between Soweto (a low-income residential area) and the Johannesburg CBD. Since its implementation, Rea Vaya Phase $1 \mathrm{~A}$ has resulted in 10\% $20 \%$ travel time savings for its users and it has assisted in the transition of minibus taxi drivers from informal employment to formal employment with Rea Vaya, doubling their annual income (Carrigan et al., 2014). However, the poorest residents of the CoJ are not significant beneficiaries of this project, only receiving $4 \%$ of the project benefits (Carrigan et al., 2014).

The question of whether BRT systems deliver equitable and pro-poor outcomes is closely related to the extent to which they enhance the accessibility of poverty populations (Venter et al., 2018). Despite the body of theoretical and empirical work that has been done on accessibility, there still appears to be a poor understanding of the social meaning of accessibility benefits and how such benefits translate into well-being improvements across different groups of a population. The use of accessibility measures to better understand the wider social benefits of transport investments is hampered by a shortage of empirical studies that examine the relationships between accessibility and social outcomes. Accessibility, its social benefits, and the various forms of exclusion are dynamic concepts which should be thoroughly assessed over time, individually and interactively. This study will attempt to fill this gap by unpacking the effects of the introduction of the Rea Vaya BRT and its associated accessibility on the well-being of Soweto residents. Through a case study of selected lowincome residential areas, the study aims to: a) measure the time-series development of accessibility, using a poverty-relevant metric, over a time period when public transport was expanded through the introduction of the BRT, b) identify and measure the extent to which investment in public transport, particularly BRT, contributed to these changes in the accessibility patterns of the urban poor, and c) attempt to identify wider social benefits, in terms of subjective well-being, of accessibility improvements driven by public transport investment.

Following this introduction, the paper is structured as follows: Section 2 provides a background on accessibility and commonly used accessibility measures, an introduction to the accessibility measuring technique used in this study, as well as the documented implications of accessibility improvements on the social fabric. Section 3 presents the data used to compute and map accessibility over the analysis years, and the data and methodology used for the regression model which estimates the average treatment effect of the BRT on well-being. Section 4 presents the results of the research in two parts: a) the time-series changes of accessibility, and b) the regression model results. Finally, Section 5 concludes the paper and provides recommendations for policy and future research.

\section{Accessibility}


In literature, accessibility has been measured to various activities or opportunities, using several modes of transport, both quantitatively and qualitatively, thus it has taken on an array of definitions over the years (Geurs \& van Wee, 2004, Martin \& van Wee, 2011). Dalvi and Martin (1976) defined accessibility as "the inherent characteristic (or advantage) of a place with respect to overcoming some form of spatially operating source of friction" (Dalvi \& Martin, 1976). Morris et al. (1979), defined accessibility as, "some measure of spatial separation of human activities". Cervero (2005) defined accessibility as "a product of mobility and proximity, enhanced by either increasing the speed of getting from point $A$ to point $B$ (mobility), or by bringing points $A$ and $B$ closer together (proximity) or some combination thereof". In this study, accessibility broadly describes the ease or difficulty of reaching a destination or opportunity from a particular location (Bocajero \& Oviedo, 2012; Venter \& Cross, 2014). Typically, opportunities refer to job opportunities, as one of the largest responsibilities of a transport system is to connect workers to jobs, and improved accessibility to employment has been linked to economic and social benefits (lacono et al., 2010; Grengs, 2010). However, destinations of employment are not the only essential destinations, thus there are studies that explore accessibility to other essential opportunities such as healthcare, schools and recreational activities as these destinations have also been tied to improvements in quality of life, refer to (lacono et al., 2010; Kenyon, 2011; Kett \& Deluca, 2016; Guzman et al., 2017). Ease or difficulty, in the broad definition of accessibility, is also known as impedance, and it is typically measured in units of travel distance and travel time. However, there is evidence of a growing inclination for including travel cost and/or competition for opportunities as measures of impedance, (e.g. Bocajero \& Oviedo, 2012; Venter \& Cross, 2014; Rodriguez et al., 2017).

There is significant social value in accessibility both as a theoretical construct and as a potential spatial planning tool; as Martens (2017) puts it, "the distinct social meaning of the transport good lies in the accessibility it confers to persons". Accessibility can aid in the identification of areas subject to transport disadvantage, subsequently answering questions of transport equity (Morris et al., 1979; Cervero, 2005), and it can act as a social indicator by identifying the level of accessibility to essential activities necessary to provide persons with a high quality of life (QoL) (Geurs \& van Wee, 2004). Ultimately, monitoring projects from a perspective of accessibility provides a more holistic view (Cervero, 2005), hence the increased interest in accessibility amongst academics (Venter \& Cross, 2014).

Accessibility is rarely measured over time; some recent examples of such studies include those of El-Geneidy and Levinson (2006); Foth et al. (2013); Koopmans et al. (2013) and Condeço-Melhorado et al. (2017). The value of a longitudinal analysis, in this study, is its ability to allow for the assessment of the accessibility impacts of transport interventions, simultaneously adjusting variables that are subject to temporal change, which would not be achieved through a cross-sectional analysis. In addition, the time-series measurement of accessibility can be used as a tool to assess the performance of land-use and transportation planning policies (El-Geneidy \& Levinson, 2006).

\subsection{Accessibility measures}

Page 3 of 27 
Geurs and van Wee (2004) highlight a number of accessibility measures in their review, amongst which two of the most commonly used measures are gravity-based measures and threshold type measures. Both of these measures have been applied extensively in transport literature across the developed and developing world, the latter including South Africa in studies by Venter and Mohammed (2013) to explore a possible relationship between transport energy consumption and accessibility in the Nelson Mandela Bay (gravity-based measure) and van Dijk et al. (2015) to explore the effects of tolls on the public transport and private vehicle accessibility across various income groups in the Cape Town metropolitan region (threshold type measure).

Although these measures have been widely applied, they do have some shortcomings. One of the shortcomings of the gravity-based models is the determination of the impedance function which assumes a commuter's perception of the rate of loss of attractiveness of an opportunity as it becomes more difficult to reach (Geurs \& van Wee, 2004; Venter \& Cross, 2014). Empirical data has revealed that a negative exponential function is the most suitable impedance function; however, the value of the exponent can take on a value anywhere between 0.5 and 3 , depending on the trip length, trip purpose and other trip attributes (Hansen, 1959). Consequently, the accessibility measure is not always easily understood by policy and decision makers (Hansen, 1959; Cervero, 2005; Venter \& Cross, 2014). The specification of the arbitrary cut-off point in threshold type measure, can be a shortfall of this measure as it only considers opportunities that fall within that arbitrary travel time or travel distance threshold, thus excluding opportunities beyond this threshold that may be considered accessible by a commuter if the individual component is incorporated into the accessibility measure.

\subsubsection{Measuring accessibility in the developing world}

In recent accessibility literature in the developing world, where affordability of transport is a significant challenge, there has been an increase in research exploring the effect of affordability of transport services on the accessibility afforded to residents. This has been executed with particular interest in low-income residents who tend to experience the financial burden of travel that is often attached to residing in the peripheries of cities, significantly dislocated from the centres of economic activity (Bocarejo S. \& Oviedo H., 2012, Venter \& Cross, 2014, Falavigna \& Hernandez, 2016, Guzman et al., 2017). Falavigna and Hernandez (2016), who analysed the affordability of public transport services for the urban poor in two cities in Latin America, found that for the poorest residents of each city to achieve the same mobility as the corresponding middle-income group, it would require them to increase their transport expenditure by more than $30 \%$. However, transport expenditure alone, does not provide a sufficient depiction of transport affordability (Venter, 2011). This is acknowledged in the accessibility measure developed by Bocarejo \& Oviedo (2012) which adapts a gravitybased measure to explicitly incorporate affordability, which is expressed as the percentage of income spent on travelling, in the impedance function. The results revealed that, in certain instances, dependent on various factors, the improvement of affordability can have a greater impact on the accessibility to opportunities than the expansion of the public transportation system. Although transport expenditure alone does not adequately reflect affordability, transport expenditure data together with objective and subjective data can allow for a valuable comparative analysis regarding the use and ability to use transport services (Venter, 
2011). Incorporating cost or affordability as a form of travel impedance in an accessibility measure can allow for the incorporation of the individual component into the measure, in terms of the financial means to commute to opportunities, ultimately providing an indication of equity across various income groups and areas and potentially informing means to achieve equity (Bocarejo S. \& Oviedo H., 2012, Falavigna \& Hernandez, 2016).

In the South African accessibility literature, there is use of traditional accessibility metrics (Venter \& Mohammed, 2013; Dijk, Krygsman et al., 2015) and even the application of newly developed accessibility measures such as the access envelope technique developed by Venter and Cross (2014). This new measure was a step towards explicitly incorporating travel cost into an accessibility measure while combatting some of the shortcomings of the more commonly used traditional accessibility measures. Travel cost considerations in accessibility measures are particularly imperative in the South African context provided the high unaffordability of public transport services. StatsSA (2014) revealed that the average household transport expenditure in Gauteng had increased from the OECD (2011) value of $21 \%$ of monthly household income to a value upwards of $26 \%$ of monthly household income for nearly half of the households in Gauteng (Gotz et al., 2014). At 21\%, Gauteng was one of the least affordable regions in Africa followed by Lagos, Nigeria whose households spent just short of $15 \%$ of their monthly income on transport.

\subsubsection{The development of the Access Envelope Technique}

The development of the access envelope technique was prompted, amongst other things, by the necessity to explicitly account for transport expenditure in the South African context, over and above the traditional travel time and distance impedance measures, in a relatively easily communicable and understandable accessibility measure. This eliminated the use of a traditional gravity-based accessibility model due to the interpretability challenge created by the use of the impedance function. The access envelope technique also makes use of actual public transport routes and frequencies as opposed to estimating the travel time and distance based on the road network (Venter \& Cross, 2014). Subsequently, this requires the analysis of an entire region within which the transport networks operate in order to capture complete routes. Therefore, the only applicable threshold would be the boundary of the selected study region instead of an arbitrary threshold based on travel distance or travel time as typically observed with the use of traditional threshold-type measures.

The access envelope technique is implemented using a Geographic Information System (GIS), a common tool for mapping accessibility, refer to (Miller \& Wu, 2000; Delamater et al., 2012; Ford et al., 2015). Venter and Cross (2014) describe the access envelope technique as, "a planning tool for measuring the impact of both transport and job or housing delivery on the location-specific affordability of job access at a community level for poor households". The following is a list of the input data required to determine the level of accessibility to employment opportunities (Venter \& Cross, 2014):

- Spatial distribution of jobs: These jobs must suit the typical education level and/or skill level of residents in the locations of origin. The spatial distribution of jobs in the CoJ was obtained from the Gauteng Transport Model job location data. 
- Potential wage levels: This is the average potential daily wage earnable in each zone across various employment sectors for low-income groups in the CoJ. The wage is increased with inflation from one analysis year to the next.

- Walking times: The access and egress walking times to and from public transport stops. The walking speed was taken as $5 \mathrm{~km} / \mathrm{h}$. Walking was also the only NMT mode that could be used to complete a commuter trip from origin to destination, however, there was no fare associated with walking, therefore, the "cost" of a walking trip was only incurred once the travel time budget was exceeded and the travel time penalty sustained.

- Waiting times: The average waiting time was accepted as half the headway of the mode used.

- Public transport costs: The public transport networks, fares and associated fare structures. The fares considered were the daily trip fares, which are slightly more expensive than the fares offered through purchasing weekly, monthly or yearly tickets. The fare structure adopted for all the modes was a linear distance-based fare structure (with the exception of the Rea Vaya BRT in 2011 which had a flat fare structure). The public transport fares were obtained from the CoJ Public Transport Record (Noble \& Bickford, 2013), and were adjusted with inflation to determine the fares across all the analysis years. The inflated fares were validated using fare data from the various public transport mode websites, with the exception of the informal minibus taxi service. For the minibus taxi, the most widely used mode in the CoJ (CoJ, 2013), inflated fares were validated through field data collection at major taxi ranks in the CoJ.

- Speed of transport mode: For road based modes, this was expressed as a percentage of the speed limit of the road section along which the mode travels.

The accessibility measure for this technique is dubbed the Net Wage After Commute (NWAC) and it describes the potential wage earnable to reach a job destination less the transport costs incurred to commute to the destination from a specific location. By explicitly including transport costs as a form of travel impedance, this technique becomes sensitive to these costs as well as operational shortfalls that force commuters to transfer along routes, which usually comes in tandem with the payment of an additional fare and travel delay (Venter \& Cross, 2014). Previous applications of Access Envelopes have examined access patterns for taxi, bus and rail in Tshwane (Venter \& Cross, 2014), and compared various BRT feeder strategies in Johannesburg (Venter, 2016). The NWAC is computed as follows:

$N W A C_{i j}^{m}=I_{j}-2 \cdot \operatorname{Fare}_{i j}^{m}-2 \cdot v_{3}$

Where, $v_{3}= \begin{cases}{\left[\left(t_{i j}^{m}-T\right) / H\right] \cdot I_{j},} & \text { if } t_{i j}^{m}>T \\ 0, & \text { otherwise }\end{cases}$

$N W A C_{i j}^{m}$ is the NWAC from zone $i$ to $j$ using mode $m$, expressed in Rands/day. $I_{j}$ is the average daily wage earnable for all jobs in zone j, expressed in Rands/day. Fare ${ }_{i j}^{m}$ is the fare incurred to travel from zone $i$ to zone $j$ using mode $m$, expressed in Rands. $t_{i j}^{m}$ is the travel time, in minutes, from zone $i$ to $j$ using mode $m . T$ is the travel time budget, which is approximately 60 minutes per direction, and $H$ is the working time per day in minutes. Based on travel behaviour literature, it is assumed that commuters in the South African context have 
a travel time budget of 60 minutes per direction; 120 minutes per day (Venter \& Cross, 2014). If commuters exceed the travel time budget, it is assumed that this reduces working hours and subsequently decreases the take-home pay. The computation of this travel time penalty is described by equation 2 . The travel time penalty acknowledges that if commuters exceed their daily travel time budget, they may compensate for this in manners that affect their income such as paying for additional hours of child care.

Figure 1 displays the average NWAC decay as a function of travel time, with and without imposing the travel-time penalty for a selected origin and destination pair that is roughly $40 \mathrm{~km}$ apart. As indicated on the graph, the travel time penalty for the same origin-destination (OD) pair will differ based on the mode used and its associated fare, speed and route. Observing the NWAC decay for the train (excluding the penalty), it is evident that for this OD pair, this is lowest cost mode as it results in the highest final NWAC, however, due to decades with no investment in the service it is dilapidated and offers uncompetitive travel times (CoJ, 2013) resulting in significant travel time penalties.

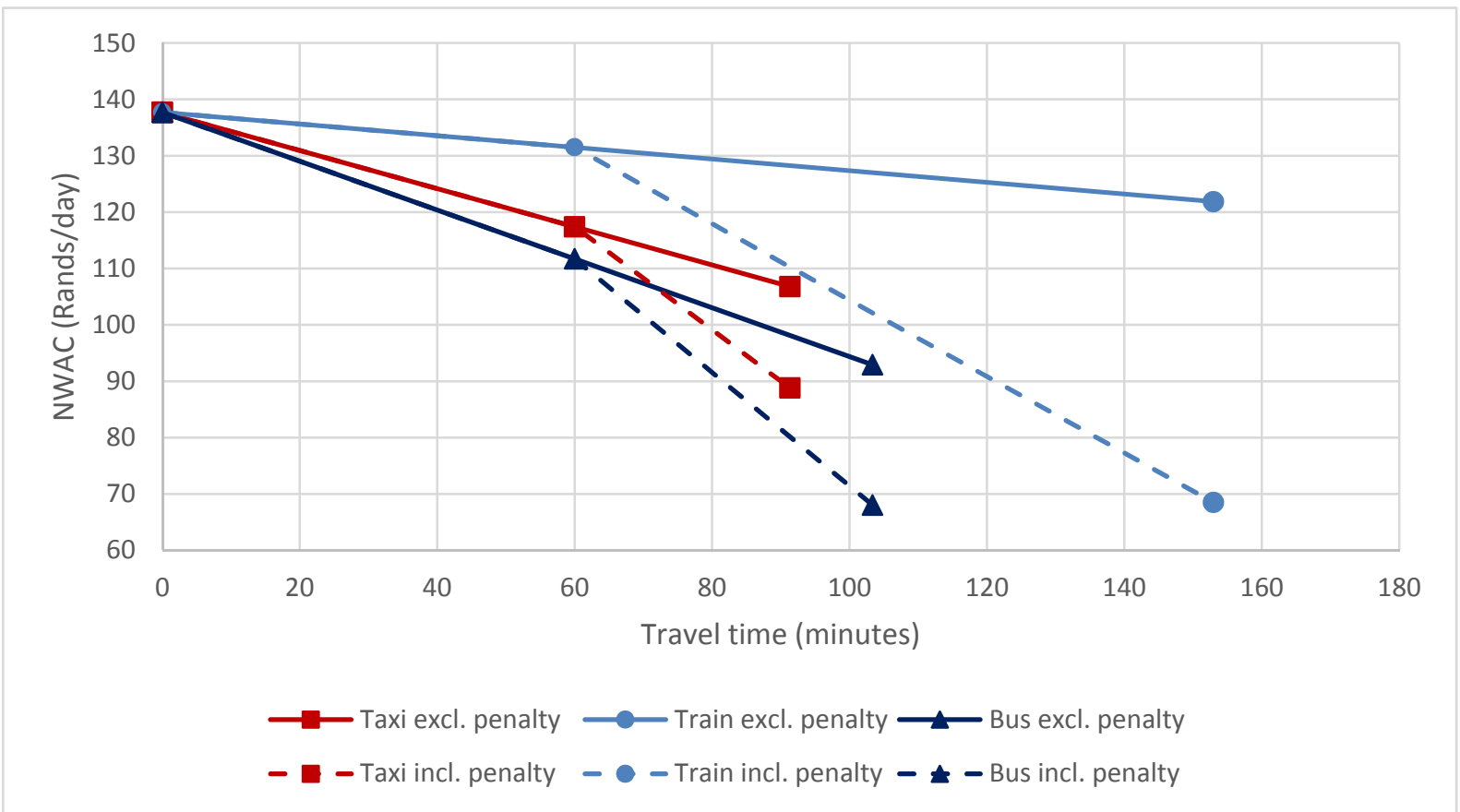

Figure 1: Average NWAC decay with travel time (including and excluding the travel time penalty)

Ideally, an accessibility measure should contain four components: i) land use, ii) transportation, iii) time, and iv) individual (Geurs \& van Wee, 2004). The NWAC measure incorporates the land-use component with the spatial distribution of jobs, the transportation component through the various public transport modes considered and the time component through the temporal impedance associated with the travel time penalty incurred for travel times that exceed the assumed travel time budget. At this stage, the access envelope technique makes assumptions regarding the earning potential of low-income commuters by matching jobs to the typical skill-set of a low-income resident. However, through the validation of such a measure, actual individual parameters can be incorporated in terms of the income earnable based on the level of education, ultimately creating a holistic accessibility measure. 
In comparison to traditional measures of accessibility, this measure is more intuitive than gravity-based models while incorporating elements of this model such as the loss of attractiveness of destinations that are further away through the travel time penalty. The access envelope technique also eliminates the need for an arbitrary travel time or travel distance threshold typically required to use a threshold-type measure by using the study region boundary as a threshold. Two shortcomings of the access envelope technique are: a) its current inability to assess accessibility to opportunities that do not have an obvious associated monetary benefit (i.e. wages), and b) it is a relatively new technique that is yet to be validated as a robust transportation planning tool. This paper adds to the existing body of knowledge of this tool and explores its capabilities in measuring accessibility over time, potentially offering guidance on the refinement of the tool for future applications, particularly in the developing world.

\subsection{Accessibility and social outcomes}

In various studies, transport accessibility has been linked to quality of life (QoL) and social exclusion (Kenyon, 2003; Preston \& Rajé, 2007; Delbosc \& Currie, 2011; Venter \& Cross, 2014). Transport-related social exclusion refers to the inability of residents to participate in the social or economic spheres of their communities due to poor accessibility to opportunities caused by insufficient provision of transport infrastructure and/or insufficient means to travel (Kenyon et al., 2002). According to Titheridge et al. (2014), low-income groups endure the most adverse effects of these causes of transport-related social exclusion such as high transport fares. Due to the combination of being located in the peripheries and the lack of sufficient opportunities within these peripheral neighbourhoods, low-income households are more prone to experience limited access to essential opportunities and the consequences thereof (Combs, 2017). This is evident in the CoJ, where low-income residents residing in the peripheries of the city travel more than $25 \mathrm{~km}$ on average to look for work, suffering a significant financial and travel time burden (Gotz et al., 2014). This provides strong rationale for investing in new PT systems to reduce exclusion. Recent research in Colombia questions whether public transport investment in BRT systems has reached the desired effect of reducing social exclusion and allowing low-income households to meet their mobility needs refer to (Jaramillo et al., 2012; Combs, 2017).

Bocajero \& Oviedo (2012) stress that transport affordability is a critical element to consider as a means to improve accessibility. Transport affordability is a key transport challenge in Gauteng; the 2011 QoL Survey revealed that one of the greatest concerns facing public transport users in the CoJ was the cost of service (Gotz et al., 2014). In fact, most low income groups resort to non-motorised transport (NMT) modes, not by choice, but because public transport is not affordable and/or it is not easily accessible (Gotz et al., 2014). The resulting consequence of inadequate transport accessibility leads to social and/or economic exclusion and compromises the QoL of residents. 


\section{Data and methodology}

The methodology covers a time-series analysis of accessibility in selected regions of the CoJ, as well as the difference-in-differences technique used to estimate the effects of BRT implementation on the well-being of Soweto residents.

\subsection{Public transport services}

The public transport services operational in the CoJ are the minibus taxi, Metrobus, Metrorail and Rea Vaya BRT. The minibus taxi is an informal service which has a nearly ubiquitous network. This mode is the second most expensive mode in the CoJ following the Metrobus (Noble \& Bickford, 2013), which also has a widespread network with average route lengths of $27.2 \mathrm{~km}$ (CoJ, 2013). Unlike the minibus taxi, this mode is subsidised by the government, however it remains the most expensive mode operating in the city. The Metrorail is the lowest cost public transport mode in the city, however, it does not serve most of the decentralised economic nodes and residential areas to the north (CoJ, 2013). The first phase of Rea Vaya (Phase 1A) became fully operational in February 2011 and it operates between Soweto and the Johannesburg CBD. Rea Vaya Phase $1 \mathrm{~A}$ constitutes of $22 \mathrm{~km}$ of bidirectional busways, $25 \mathrm{~km}$ of mixed traffic lanes used by complimentary buses, $29 \mathrm{~km}$ of mixed traffic lanes used by feeder buses and 31 stations. Annual passengers in 2011/2012 were 8.8 million, which increased to 10.2 million in 2012/2013 (CoJ, 2013). The public transport routes and associated fares for all operational modes in the CoJ were determined for the years 2009, 2011 and 2013.

Table 1 reflects the modes considered in each analysis year as well as the corresponding change in fares. In 2009, only three modes were considered. In 2011, four modes were considered and at this stage Rea Vaya used a flat fare structure which was as follows: the cost of using a feeder route was R4.50; the cost of using a trunk route was R8.50; and the cost of using both the feeder and trunk route was R12.00. In 2013, the same four modes as in 2011 were considered, however, Rea Vaya BRT used a distance-based fare structure following the introduction of the Rea Vaya smartcard in 2012.

Table 1: Public transport modes and associated fares

\begin{tabular}{|c|c|c|c|c|c|c|}
\hline Year & Fare & $\begin{array}{c}\text { Minibus } \\
\text { taxi }\end{array}$ & Metrorail & Metrobus & $\begin{array}{l}\text { BRT Phase } \\
\text { 1A Trunk }\end{array}$ & $\begin{array}{l}\text { BRT Phase } \\
\text { 1A Feeder }\end{array}$ \\
\hline \multirow[b]{2}{*}{2009} & Base fare ${ }^{a}$ & 5.88 & 3.9 & 6.65 & \multirow{2}{*}{\multicolumn{2}{|c|}{ No BRT }} \\
\hline & $\begin{array}{l}\text { Distance-based } \\
\text { fare }^{\mathbf{b}}\end{array}$ & 0.17 & 0.050 & 0.30 & & \\
\hline \multirow[b]{2}{*}{2011} & Base fare ${ }^{a}$ & 6.95 & 4.61 & 7.86 & 8.50 & 4.50 \\
\hline & $\begin{array}{l}\text { Distance-based } \\
\text { fare }^{\mathbf{b}}\end{array}$ & 0.20 & 0.059 & 0.35 & - & - \\
\hline \multirow[b]{2}{*}{2013} & Base fare ${ }^{a}$ & 7.35 & 4.87 & 8.32 & \multicolumn{2}{|c|}{5.28} \\
\hline & $\begin{array}{l}\text { Distance-based } \\
\text { fare }^{\mathbf{b}}\end{array}$ & 0.21 & 0.063 & 0.37 & \multicolumn{2}{|c|}{0.24} \\
\hline
\end{tabular}

a: measured in Rands

b: measured in Rands/km 


\subsection{Net Wage After Commute (NWAC)}

The access envelope technique computes the accessibility from a selected origin zone to all other zones on a study surface. The NWAC metric seeks to reflect the objective of a worker or work seeker that trades off travel time and cost in such a way as to maximise his/her takehome pay at each given location and doing so might require selecting a combination of modes by which to travel to the destination. In practical terms, maximising the take-home pay will typically be achieved through the use of the lowest cost mode (including walking); however, once the travel time budget (in the present case 60 minutes per direction) is exceeded, higher cost but faster motorised modes may be used in order to avoid encroaching onto the available working time for the day.

To compute the NWAC, the CoJ was divided into roughly 19000 hexagonal zones and the output of the accessibility analysis from a selected origin zone is a map of the study surface graphically displaying the NWAC at every zone on the study surface from the selected origin zone. Therefore to allow for ease of comparison between different origin zones and over the analysis years, the following summary measures were determined to capture the effects of transport affordability, job location and travel times on job accessibility:

- The number of jobs accessible with NWAC greater than R85/day: This gives an indication of the number of jobs a commuter can access while retaining a reasonable NWAC (assumed to be R85/day). This amount of R85/day is based on the assumption of a single breadwinner and a household size of four (the average household size in the Gauteng City-Region based on the 2009, 2011 and 2013 QoL surveys). A sole breadwinner in such a household will have to take home R85 a day to ensure that each individual in the household lives above the lower bound poverty line (ignoring equivalence scales). The lower bound poverty line, as defined by StatsSA (2014), is the line below which food items are sacrificed to afford other nonfood goods such as transport.

- The number of jobs accessible within $\mathbf{6 0}$ minutes of travel time: This gives an indication of the spatial distribution of jobs within 1 hour of travel time from the origin. Origins that score high are either within close proximity to economic nodes and/or are well-served served by faster modes of public transport.

- Average NWAC of the closest 200,000 jobs: This gives an indication of the distribution of the NWAC in the immediate surrounding of the origin location while controlling for the number of jobs. Origins that score high are either surrounded by high paying jobs or low transport costs in conjunction with shorter travel times.

\subsection{Time-series development of accessibility}

A time-series analysis of accessibility, defined by the abovementioned summary measures, was conducted to determine the changes of accessibility over time in the various low-income regions. The residential areas selected for the case study were: Alexandra, Soweto, Diepsloot, Orange Farm, Lawley, Lenasia, Lenasia South and Ennerdale (see Figure 2). Non-white groups were forcefully relocated to these areas, with the exception of Alexandra, during the apartheid era. Alexandra residents were successfully able to resist relocation (Todes, 2012), however, like all the other areas, Alexandra still suffered from poor 


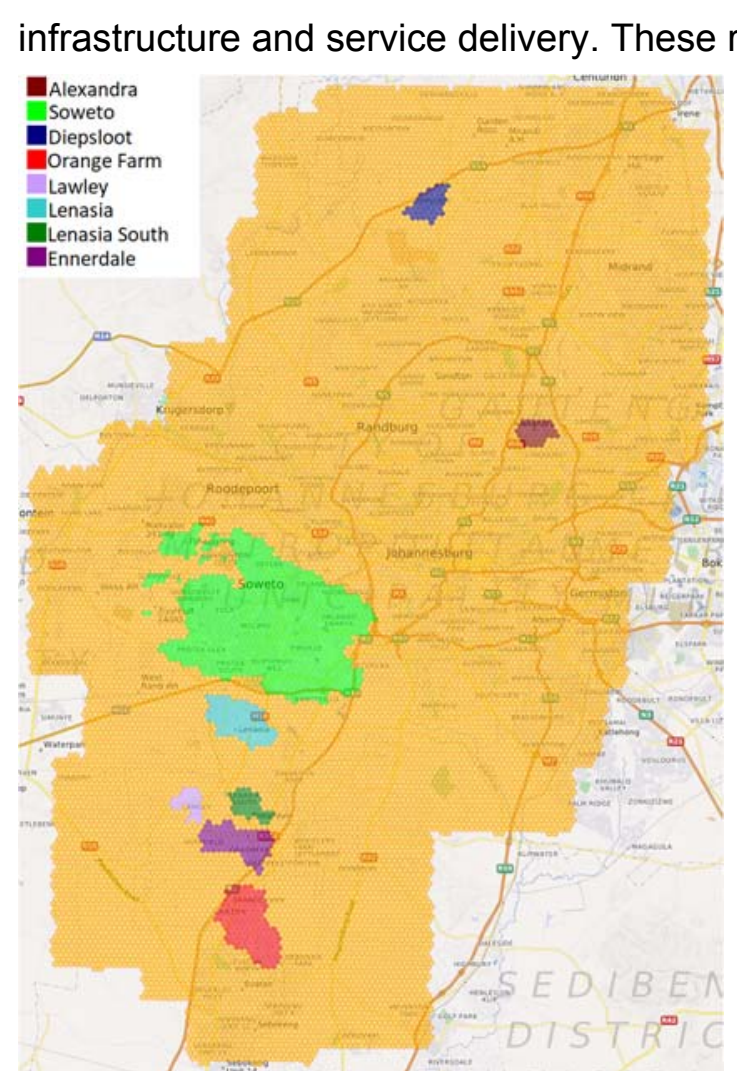

Figure 2: Analysis regions in the CoJ accommodate predominantly low-income households, which is the main premise for their selection. An additional reason for the selection of Soweto, in particular, is the increased likelihood of observing the changes brought about by the BRT implementation in that region. From each of the selected analysis regions, 30 or more sample zones were randomly selected and the NWAC surface computed for each origin. For each of these selected regions, average summary measures were determined and compared over time.

A four quadrant plot was used to understand the interaction between two of the accessibility summary measures as well as the changes of that interaction over time for each of the lowincome residential areas. The $x$-axis is defined by the number of jobs accessible with NWAC>R85 (NWAC index) and the $y$-axis is defined by the number of jobs accessible within 60 minutes of travel time (TT index). Each summary measure was standardized about the overall average which was taken across all regions over all three analysis years. Therefore, a value of 0 on the plot indicates that the average accessibility measure for that region is equal to the overall average and a value of 1 indicates that the average accessibility measure for that regions is $100 \%$ greater than the overall average. $A$ schematic of the four quadrant plot is displayed in Figure 3, detailing the accessibility attributes of the various quadrants. A cross-sectional analysis was conducted to illustrate the effects of geographical location on the distribution of accessibility amongst region residents. This was done through a cumulative distribution plot where the $\mathrm{x}$-axis recorded the percentage of jobs accessible with NWAC>R85 on the entire study surface and $y$-axis recorded the cumulative percentage of zones in each region. This provides an indication of the total number of opportunities available on study surface as well as the extent to which these are accessible within the various regions.

Although a time-series analysis has its benefits, the lack of sufficient time-series data to accurately capture the temporal change of the input variables presents a challenge for a longitudinal study. In this study, wage levels and transport fares were adjusted over time, but the spatial distribution of jobs was assumed to have remained constant as no better information was available. It was unlikely, however, that job densities would have changed substantially enough over the short analysis period to affect the results. 


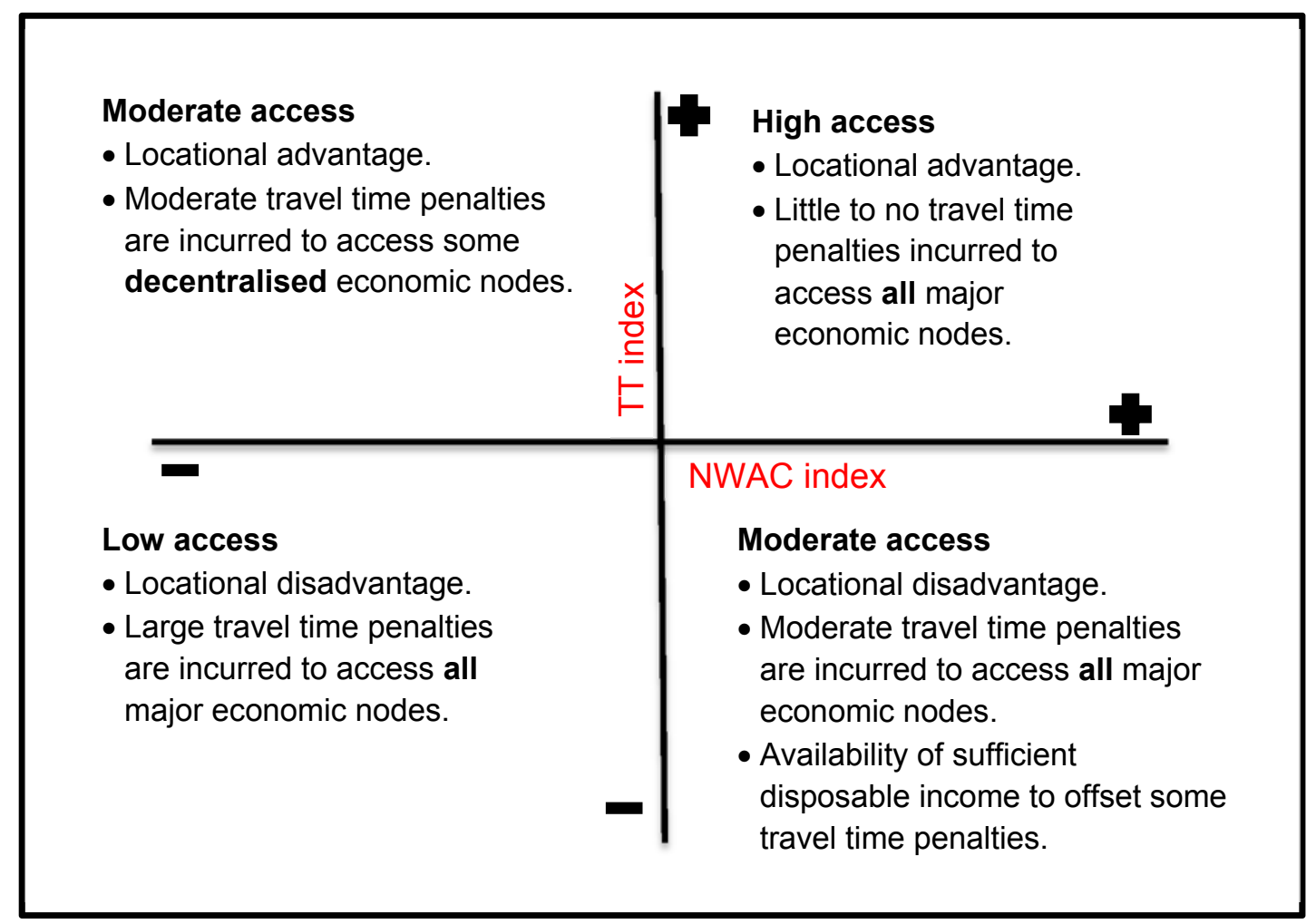

Figure 3: Four quadrant plot schematic of accessibility summary measure indices

\subsection{Estimating the impact of BRT implementation on subjective well-being}

\subsubsection{Research design}

A difference-in-differences (DID) approach was adopted to explore the effects of accessibility improvements driven by public transport investment in the BRT in Johannesburg on the wellbeing of Soweto residents. DID is one of a few commonly used statistical techniques that estimate average treatment effects (ATEs); previous applications of the DID methodology in transportation research include Bocajero et al. (2013) and Combs (2017). Two other commonly used techniques are propensity score matching and regression discontinuity design. Propensity score matching attempts to estimate the effect of a treatment by accounting for all the observed variables that predict receiving the treatment. Although this technique controls for selection bias, its main shortcoming is that it cannot account for the unobserved variables that may affect receiving a treatment, and this could subsequently introduce additional bias (Blackford, 2009). This approach may be particularly problematic in the estimation of the ATE of a transportation project, whose route placement is typically based on a myriad of variables, both observable and unobservable. The time and group dimensions of a difference-in-differences approach allows for accounting for some of these unobservable variables (provided they are constant over time) depending on the method of selection of the treatment group, and the model may be strengthened by adding observed individual-specific covariates in the model (Lechner, 2010). 
Unlike the DID design which assumes the control and treatment group would follow a similar trend in the absence of the treatment, the regression discontinuity design is applicable in experiments where there is a specified cut-off criteria pre-treatment to identify participants most in need of the treatment, thus maximising the difference in the outcome variable between the control and treatment group pre-treatment (William, 2006). It is not suitable to assess the average treatment effect in this study as there was no known specified cut-off criterion pre-treatment to ensure the route was placed where it was most needed within Soweto.

The DID model estimates the effect of implementation of the BRT in Soweto on the wellbeing of Soweto residents. Satisfaction was taken as a proxy for well-being; in-fact, the terms have been used interchangeably as both capture the subjective evaluation of one's life (Diener et al., 2009; Delbosc, 2012). The effect of the treatment is estimated on two areas of satisfaction: a) Satisfaction with life as a whole and, b) satisfaction with the amount of free time the respondent has available to him- or herself. The first outcome variable was selected on the premise that it attempts to capture one's satisfaction with life holistically and the model will estimate if the BRT had any effect on this. The second outcome variable was selected on the premise that the BRT in the CoJ has been tied to travel time savings (Carrigan et al., 2014) and the model will estimate if the BRT increased satisfaction in this area of a respondent's life as a result of these savings. A DID regression model was designed such that it explores the effect of BRT implementation on these outcome variable for a sample of Soweto residents, while controlling for selected objective well-being predictor variables such as employment, education, household infrastructure and accessibility to jobs. Each outcome variable was modelled separately using the same predictor variables.

\subsubsection{Data}

Observations to carry out the statistical analysis were obtained from the QoL surveys conducted by the Gauteng City Region Observatory (GCRO) biennially, since 2009, in an attempt to assess the subjective and objective well-being of the Gauteng City-Region (GCR) residents. Survey respondents were sampled from the adult population to be representative at the electoral ward level (Mushongera et al., 2015). For additional information on the GCRO's QoL survey, validity of the QoL index and its indicators, and comparability over time, refer to Greyling (2013) and Everatt (2017).

The time considered before and after BRT implementation for the DID regression model is 2009 and 2013, respectively. The treatment group comprises of QoL survey respondents in Soweto residing within $800 \mathrm{~m}$ of feeder and/or trunk route stations while the control group comprises of QoL survey respondents in Soweto further than $800 \mathrm{~m}$ from the stated stops and/or stations. This $800 \mathrm{~m}$ catchment is informed by local guidelines (CSIR, 2000), which hold that in residential areas, no resident should walk more than $400 \mathrm{~m}$ (roughly 5 minutes) to the nearest bus stop (translating to an $800 \mathrm{~m}$ stop spacing). However, given that the BRT provides a service that is superior to existing road-based public transport modes in terms of improved safety and improved travel time, the maximum walking distance was relaxed to $800 \mathrm{~m}$. In addition, Table 2 reflects the walking distances to the first public transport stop reported by respondents of the 2009 QoL survey. The table only reflects the responses of those for whom this question was applicable which was 4456 respondents out of a total of

Page 13 of 27 
6636. It is evident that the largest proportion of respondents $(79 \%)$ walk for less than 10 minutes to the first transit stop.

Table 2: Walking distances to the first transit stop (Source: GCRO QoL survey 2009)

\begin{tabular}{c|cc}
\hline Walk time $\mathbf{t}$ (minutes) & Observations & Percentage \\
\hline $\mathrm{t}<5$ & 1859 & $42 \%$ \\
\hline $5 \leq \mathrm{t}<10$ & 1667 & $37 \%$ \\
\hline $10 \leq \mathrm{t}<20$ & 640 & $14 \%$ \\
\hline $20 \leq \mathrm{t}<30$ & 154 & $3 \%$ \\
\hline $\mathrm{t} \geq 30$ & 136 & $3 \%$ \\
\hline Total number of respondents & 4456 & \\
\hline
\end{tabular}

Each QoL survey has a subjective well-being section which asks a number of questions across various areas of the respondent's life; it is from this section that the two outcome variables (satisfaction with life and satisfaction with the amount of free time available) are observed. For each of the questions, responses are provided on an ordinal scale from 1 ("Very satisfied") to 5 ("Very dissatisfied"). Subsequently, an ordered logistic regression model was used to model each dependent variable. An often violated, and thus restrictive assumption of this regression technique is that of proportional odds, in which case alternative techniques are available to model the data (Lui \& Koirala, 2012). The assumption of proportional odds was met in both models as the test of parallel lines was not statistically significant at the 0.05 significance level, thus resulting in failure to reject the hypothesis that the assumption holds (refer to Table 7 ). Therefore, the ordered logistic regression was deemed an appropriate technique to model the data.

The first model estimates the effect of the treatment on the respondents' satisfaction with life as a whole, and the second model estimates the effect of the treatment on the respondents' satisfaction with the amount of free time they have available. Due to the very few observations $(<2 \%)$ in the extreme categories of the ordinal scale, being "Very satisfied" and "Very dissatisfied", the ordinal scale was aggregated from 5 categories to the following 3 categories:

- Satisfied: assigned to those who were either satisfied or very satisfied on the original 5 category ordinal scale,

- Neutral: assigned to those who were neutral on the original 5 point ordinal scale, and

- Dissatisfied: assigned to respondents who were either dissatisfied or very dissatisfied on the original 5 point ordinal scale.

The observations in each of the final categories can be seen in Table 3 . The numbers in brackets adjacent to the stated categories represent the order of the categories as used in the regression model.

It should be noted that any measurement of subjective well-being is imperfect due to the inability to capture all person-specific factors, and the possibility of large error terms due to day-to-day variations in latent phenomena. 
Table 3: Summary of observations in each category of the outcome variables

\begin{tabular}{c|ccc}
\hline $\begin{array}{c}\text { Dependent } \\
\text { variable }\end{array}$ & Category & $\begin{array}{c}\text { Number of } \\
\text { observations }\end{array}$ & $\begin{array}{c}\text { Marginal } \\
\text { Percentage }\end{array}$ \\
\hline \multirow{2}{*}{ Life as a } & Satisfied [1] & 266 & $62.9 \%$ \\
\cline { 2 - 4 } whole & Neither [2] & 56 & $13.2 \%$ \\
\cline { 2 - 4 } & Dissatisfied [3] & 101 & $23.9 \%$ \\
\hline \multirow{4}{*}{ Free time } & Satisfied [1] & 324 & $76.6 \%$ \\
\cline { 2 - 4 } & Neither [2] & 36 & $8.5 \%$ \\
\cline { 2 - 4 } & Dissatisfied [3] & 63 & $14.9 \%$ \\
\hline
\end{tabular}

\subsubsection{Regression model}

The general form of the ordered logistic regression is shown in equations 4 . The outcome variable $Y$ has $k$ categories, and is described by a vector of predictors $\boldsymbol{X}$, with coefficients $\beta_{1}$ to $\beta_{p}$. The probability of a category $\mathrm{j}$ is given by $\operatorname{Pr}(\mathrm{Y}=\mathrm{j})$ for $\mathrm{j}=1,2, \ldots, \mathrm{k}$. The logit, seen in equation 4 between the equals signs, is the log of the odds that an event occurs. $\alpha_{j}$ is referred to as the threshold and it is similar to the y-intercept in linear regression, however, in this case each logit has an intercept.

$\lambda_{j}(\boldsymbol{x})=\ln \left\{\frac{\sum_{1}^{j} \operatorname{Pr}(Y=j \mid x)}{\sum_{j+1}^{k} \operatorname{Pr}(Y=j \mid \boldsymbol{x})}\right\}=\alpha_{j}+\beta_{1} \cdot x_{1}+\beta_{2} \cdot x_{2}+\cdots+\beta_{p} \cdot x_{p}$

$\lambda_{j}(\boldsymbol{x})=\alpha_{j}+\beta_{1} \cdot$ year $+\beta_{2} \cdot B R T+\beta_{3} \cdot$ respondent characteristics $+\beta_{4} \cdot A c c+\beta_{5} \cdot$

$A c c B R T+\beta_{6}($ year $\cdot B R T)+\beta_{7}(B R T \cdot P T$ user $)+\beta_{8}(B R T \cdot A c c B R T)+\varepsilon$

$j=1, \ldots, k-1$

In the model designed for this study (refer to equation 5) the outcome variable, which has 3 categories, is estimated by the main effects of predictor variables as well as some interactions between them. Table 4 shows all of these variables and the effects they capture on the outcome variable.

Table 4: Independent variables of the regression model

\begin{tabular}{c|c|l}
\hline Coefficient & Variable & \multicolumn{1}{c}{ Captures } \\
\hline$\beta_{1}$ & $\begin{array}{c}\text { Year } \\
0: 2009 \\
1: 2013\end{array}$ & $\begin{array}{l}\text { The general time trend from 2009 to 2013 which captures factors } \\
\text { that would result in a change in the outcome variable even in the } \\
\text { absence of the treatment }\end{array}$ \\
\hline$\beta_{2}$ & $\begin{array}{c}\text { BRT } \\
\text { 0: Control group } \\
\text { 1: Treatment group }\end{array}$ & $\begin{array}{l}\text { The possible unobserved differences between the control and the } \\
\text { treatment group pre-treatment. }\end{array}$ \\
\hline$\beta_{3}$ & $\begin{array}{c}\text { Respondent } \\
\text { characteristics }\end{array}$ & $\begin{array}{l}\text { The individual-specific characteristics of the respondents that may } \\
\text { affect satisfaction. These include: public transport usage, } \\
\text { employment, education, sanitation, water supply, electricity supply, } \\
\text { food security, travel times, health limitations }\end{array}$ \\
\hline$\beta_{4}$ & Acc & The effect of a unit increase in TT accessibility. \\
\hline
\end{tabular}




\begin{tabular}{c|c|l}
\hline$\beta_{5}$ & AccBRT & $\begin{array}{l}\text { The effect of a unit increase in the TT accessibility offered by the } \\
\text { BRT }\end{array}$ \\
\hline$\beta_{6}$ & year•BRT & $\begin{array}{l}\text { The treatment effect, which is the effect of being within 800m of } \\
\text { BRT stops/stations relative to being further out, post-treatment }\end{array}$ \\
\hline$\beta_{7}$ & BRT•PT user & $\begin{array}{l}\text { The effect of being a frequent public transport (PT) user in the } \\
\text { treatment group relative to being a non-frequent PT user in the } \\
\text { control group, post-treatment }\end{array}$ \\
\hline$\beta_{8}$ & BRT•AccBRT & $\begin{array}{l}\text { The effect of a unit increase in BRT TT accessibility for the } \\
\text { treatment group relative to a unit increase for the control group }\end{array}$ \\
\hline
\end{tabular}

Year and $B R T$ are categorical variables that took on two possible values each as seen in Table 4. Respondent characteristics is a vector of measures capturing a range of characteristics that may influence a respondent's subjective well-being. The selection of these variables was predominantly informed by Wright's report (2008) listing indicators of poverty based on socially perceived necessities as well as the economic and non-economic indicators of well-being (Sumner, 2004). However, the variables were restricted to the questions set out in the QoL surveys and were further reduced accordingly to avoid multicollinearity. The variable Acc is the TT accessibility summary measure computed for each zone and assigned to the households within that zone. AccBRT is the TT accessibility provided by the BRT only, computed for each zone and assigned to the households within that zone.

\section{Results}

\subsection{Changes in Accessibility}

The four quadrant plot displayed in Figure 4 reflects the accessibility levels for all eight selected regions throughout the three analysis years. 2009 is the left most reading, 2013 is the right most reading and the 2011 is the centre reading for each region. It is immediately evident for each region that the NWAC index increases from one analysis year to the next, while the TT index decreases from one analysis year to the next, with Soweto being the only exception to the latter. The increase in the NWAC index is predominantly driven by an increase in potential wages earnable, which translates to increased relative affordability of public transport to either commute using higher cost but faster motorised modes or to commute over longer distances using the same mode while retaining a reasonable takehome pay. The decrease in the TT index, which is proportionally lower than the corresponding increase in the NWAC index, is predominantly driven by the increase in fares from one analysis year to the next, which results in an increase in the number of walking trips and an increase in the distance over which walking maximises the NWAC, decreasing the overall number of jobs accessible within one hour of travel time.

The study regions in the high accessibility quadrant are Alexandra, Soweto and Lenasia. Figure 2 shows that these are the most centrally located regions that boast shorter distances to the Johannesburg CBD than other regions. Alexandra, however, reflects the highest accessibility due to its close proximity to not only the CBD but also key activity nodes with ample economic opportunities to the north of the CBD such as Sandton, Midrand and Randburg, which can all be accessed within the travel time budget from Alexandra. 
Subsequently, Alexandra also reflects the highest accessibility in terms of the average NWAC of the closest 200,000 jobs (R123 per day on average, see Figure 4). However, the effect of increasing relative affordability is not as evident for Alexandra as it is in the other regions. For a high accessibility township like Alexandra, an increase in the relative affordability of public transport generally allows for longer commutes towards the peripheries of the CoJ while retaining a reasonable take-home pay. With fewer job opportunities located in the peripheries, this only has a minimal effect on accessibility, in terms of the NWAC index. This illustrates that improving accessibility to regions with limited economic activity will have a similarly limited effect on the accessibility patterns of a region. In addition, this suggests that the marginal benefits of improving accessibility to opportunities from regions with already high levels of accessibility to these opportunities, such as Alexandra, are relatively low. This is consistent with the findings of López (2007) and Axhausen (2008).

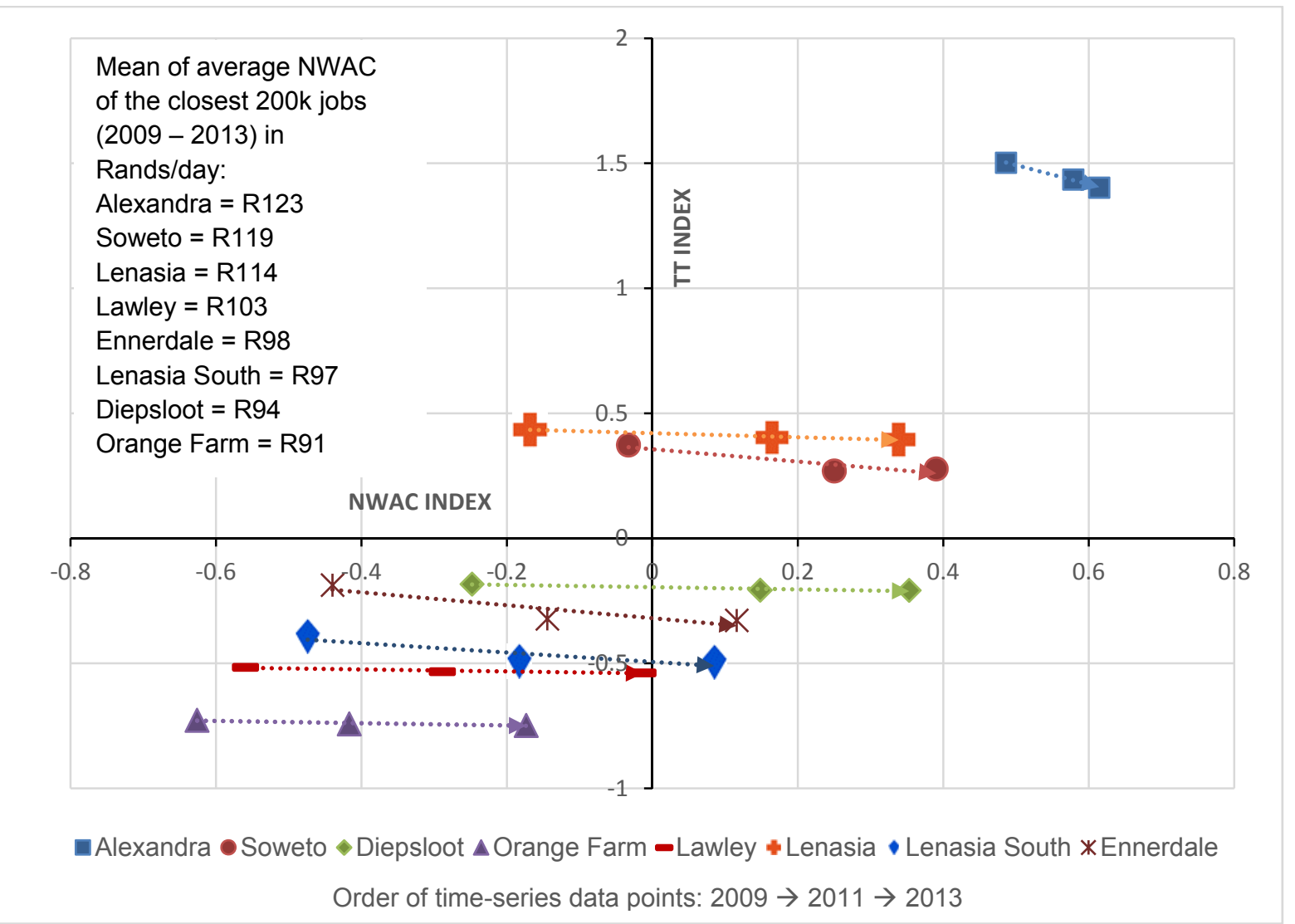

Figure 4: Quadrant plot of accessibility summary measure indices

The majority of the selected regions (Diepsloot, Lenasia South, Lawley, Orange Farm and Ennerdale) all fall within the low and/or moderate accessibility quadrants in the lower half of the quadrant plot. Orange Farm recorded the lowest accessibility values; located in the southern peripheries of the CoJ (see Figure 2), it is the region that is furthest removed from the Johannesburg CBD and the decentralised economic nodes to the north of the CBD. An increase in wages from one analysis year to the next allowed for a slight shift from the lowfare and low-speed Metrorail to the minibus taxi and commutes over longer distances while retaining a reasonable take-home pay which significantly increased the number of jobs accessible with a reasonable NWAC from Orange Farm, particularly towards the north of the CoJ (see Figure 5). This reinforces the observations made for Alexandra in that Orange 
Farm and the other low accessibility regions demonstrate that accessibility patterns are largely altered by improved accessibility to regions of high economic activity. The low-fare Metrorail, which predominantly runs in the East-West direction and towards the South and South-West of the city, serving Orange Farm, could act as a buffer against fare increases on other modes, particularly due to its low fares. However, with its relatively low operating speed over long distances such as those encountered from Orange Farm to the Johannesburg CBD, large travel time penalties are incurred, significantly reducing the NWAC. Low-cost public transport modes can play a role in improving accessibility patterns, however, this is only possible if they offer their service at competitive speeds. In other words, the low-cost accessibility benefit of transit modes can be eroded by low-speeds and/or excessively long travel distances.
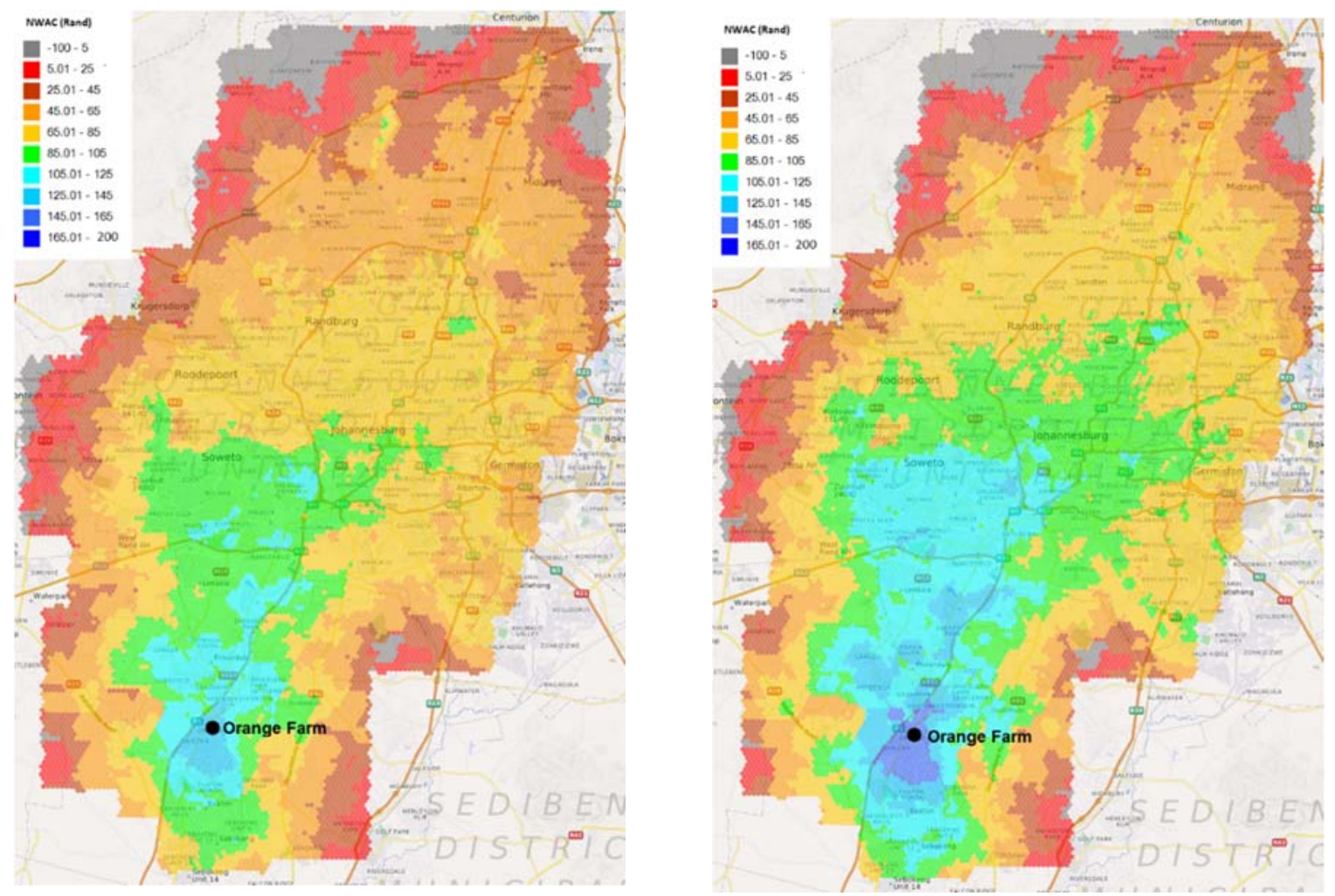

Figure 5: NWAC surface for Orange Farm (2009 and 2013)

The BRT was introduced to the city during the analysis period and Soweto became the only one of the eight regions well-served by all 4 public transport modes in the city. Figure 4 reveals that Soweto is the only region for which the number of jobs accessible within 60 minutes travel time increased, though minimally, from $2011(0.27)$ to $2013(0.28)$. This is attributed to the BRT and the speed improvement it provides (over Metrorail and NMT) at a lower cost than the minibus taxi and Metrobus. Therefore, the BRT ensures that even as fares increase, accessibility (in terms of the travel time index) does not decline as it provides a lower cost alternative to the minibus taxi and Metrobus while maintaining similar travel times. However, an increase of 0.01 in the TT index, which is equivalent to 6,653 jobs, is fairly small. A paired samples t-test of the TT accessibility revealed a statistically significant difference between the 2009 and 2011 TT accessibility values ( $p$-value $<0.01$ ), however, 
there was no evidence of a statistically significant difference between the 2011 and 2013 TT accessibility values $(p$-value $=0.193$ ) for the entire Soweto sample.

When the BRT was introduced to the CoJ, it was competing against relatively robust public transport systems (the minibus taxi in particular), which has a large catchment area in comparison to the BRT. The BRT Phase $1 \mathrm{~A}$ also serves an already well-served route, which is the Soweto - CBD route, thus duplicating existing services with no real integration between the public transport modes and consequently creating challenges in leveraging this investment. There were efforts towards milder forms of integration of modes through the process of restructuring the minibus taxi network at the advent of the BRT planning process when $\mathbf{3 0 0}$ former minibus taxi operators surrendered their minibus taxis to the city for scrapping, in exchange for roughly R50,000 to buy a stake in the company that would operate the Rea Vaya Phase $1 \mathrm{~A}$. Consequently, former minibus taxi drivers became employed as Rea Vaya drivers (Mokonyama \& Mubiwa, 2014). However, it appears more rigorous methods of modal integration may be necessary to observe significant changes in accessibility patterns brought about by the BRT in conjunction with existing services.

It is also evident that although the BRT was fully operational from 2011, its effect on accessibility only became notable on Figure 4 in 2013. This can be attributed to the change in the BRT fare structure from 2011 to 2013 in tandem with increasing fares of other modes with similar operating speeds. Therefore, in 2011, the BRT was a relatively expensive mode and thus rarely the NWAC maximising mode.

The value of this analysis lies in its ability to inform whether or not accessibility is actually improving over time, as required by policy and informing, within the parameters of the measure, how accessibility can be improved even in the absence of transport investments. However, we do observe two accessibility summary measures that depict contrasting behaviour over time, making it challenging to conclusively state whether or not accessibility improved over the analysis years, with the exception of Soweto from 2011 to 2013. This suggests that the reported results are sensitive to the accessibility summary measures utilised and further research is necessary, particularly in terms of validating the tool to gain a deeper understanding of the behaviour of these two summary measures on the ground.

\subsection{Well-being outcomes}

Each outcome variable had three categories which were numbered as follows: 1 "Satisfied", 2 - "Neutral", and 3 - "Dissatisfied", therefore a respondent who responds within a higher numbered category is deemed less satisfied than a respondent whose response is within a category with a lower number. Table 5 reflects the observations of each outcome variable for both the treatment and control group, pre- and post-treatment. Arbitrarily using mode as a measure of central tendency, it is evident from Table 5 that satisfaction with life as a whole improved from 2009 to 2013 for both groups whereas satisfaction with the amount of free time remained unchanged. 
Table 5: Change in the outcome variables from 2009 to 2013

\begin{tabular}{|c|c|c|c|c|c|c|c|c|}
\hline & \multicolumn{4}{|c|}{ Control group } & \multicolumn{4}{|c|}{ Treatment group } \\
\hline & \multicolumn{2}{|c|}{2009} & \multicolumn{2}{|c|}{2013} & \multicolumn{2}{|c|}{2009} & \multicolumn{2}{|c|}{2013} \\
\hline & $n^{a}$ & Mode & $n^{a}$ & Mode & $\mathrm{n}^{\mathrm{a}}$ & Mode & $n^{a}$ & Mode \\
\hline Life as a whole & \multirow{2}{*}{46} & 3 & \multirow{2}{*}{133} & 1 & \multirow{2}{*}{62} & 3 & \multirow{2}{*}{182} & 1 \\
\hline Free time & & 1 & & 1 & & 1 & & 1 \\
\hline
\end{tabular}

a: number of observations

The Mann-Whitney U-test, a non-parametric alternative to the unpaired t-test, was used to test if there was a significant difference in each outcome variable for each group from 2009 to 2013. The null hypothesis of the Mann-Whitney U-test, for the control or treatment group, is that the 2009 respondents have the same distribution of the selected outcome variable as the 2013 respondents. The results for both outcome variables reveal that there is a statistically significant difference in the variable from 2009 to 2013 for both the control and treatment group ( $p$-value $<0.05$ ), either in the measure of central tendency, spread and/or shape of the outcome variable. The only exception to this observation was the control group respondents for the outcome variable satisfaction with free time with $p=0.051$, refer to Table 6.

Table 6: Results of Mann-Whitney U-Test

\begin{tabular}{r|c|c|c|c}
\hline \multirow{2}{*}{} & \multicolumn{2}{|c|}{ Life as a whole } & \multicolumn{2}{c}{ Free time } \\
\cline { 2 - 5 } & Control & Treatment & Control & Treatment \\
\hline $\mathrm{Z}$ & -4.809 & -6.034 & -1.956 & -4.238 \\
\hline p-value (2-tailed) & 0.000 & 0.000 & 0.051 & 0.000 \\
\hline
\end{tabular}

Table 7 reflects the results of the DID regression model. Exponentiation of the coefficients of the predictor variables $(\beta)$ will give the odds ratio of each predictor variable found in the columns with heading $\operatorname{Exp}(\beta)$. For a continuous predictor variable, the odds ratio provides the odds of moving up a category on the ordinal scale given a unit increase in the predictor variable. For a categorical predictor variable, the odds of moving up a category are provided relative to a reference category, which is also provided Table 7 . For example, for the predictor variable BRT and the well-being outcome satisfaction with life as whole, the odds of the control group being less satisfied are 1.31 times higher than the treatment group, however, this result is not statistically significant at the 0.05 significance level.

The results of the model with outcome variable satisfaction with life as whole, reveal that the predictors that have a statistically significant effect on this variable are year, employment, supply of basic services, specifically water in this case, food security and travel time for the most frequently completed trip. The results suggest that the odds of 2009 respondents being less satisfied were 4.02 times greater than 2013 respondents, corroborating the observation made in Table 5. This could be due to general changes that took place over the 2009 to 2013 time period. There was significant investment in Soweto post-2000 from all spheres of government in an attempt to restructure the township by providing adequate amenities, housing, electricity, malls and places of leisure. Some of this investment was driven by the 2010 FIFA World Cup hosted in South Africa which required the upgrade of two stadiums within Soweto and the upgrade of a premier stadium just adjacent to the township; this is 
believed to have had spin-off benefits for the Soweto and its residents (Harrison \& Harrison, 2014), possibly contributing to a reduction in dissatisfaction from 2009 to 2013 . Relative to unemployed job seekers, both employed and unemployed (not seeking) respondents are better off in terms of life satisfaction, with odds of less than half of being less satisfied than job seekers. The results also reveal that the odds of respondents who frequently travel for longer than one hour being less satisfied were 2.16 times of those who travel for less than an hour, suggesting that excessive travel times do have adverse effects on subjective wellbeing.

Table 7 : DID regression model results

\begin{tabular}{|c|c|c|c|c|c|c|}
\hline \multirow{2}{*}{$\beta$} & \multirow{2}{*}{ Predictor variable } & \multirow{2}{*}{ Reference category } & \multicolumn{2}{|c|}{ Life as a whole } & \multicolumn{2}{|c|}{ Free time } \\
\hline & & & $\operatorname{Exp}(\beta)$ & SE & $\operatorname{Exp}(\beta)$ & SE \\
\hline$\beta_{1}$ & Year & 2013 & $4.02^{* *}$ & 0.387 & 2.16 & 0.423 \\
\hline$\beta_{2}$ & BRT & Treatment group & 1.31 & 0.429 & 0.56 & 0.492 \\
\hline \multirow{12}{*}{$\beta_{3}$} & PT User & $\begin{array}{c}\text { Frequent public transport } \\
\text { user }\end{array}$ & 1.19 & 0.362 & 0.57 & 0.424 \\
\hline & Employed & \multirow[b]{2}{*}{ Unemployed job seeker } & $0.49^{* *}$ & 0.261 & 1.22 & 0.276 \\
\hline & $\begin{array}{c}\text { Unemployed (not } \\
\text { seeking) }\end{array}$ & & $0.40^{* *}$ & 0.306 & 0.53 & 0.356 \\
\hline & $\begin{array}{c}\text { No education/primary } \\
\text { school education }\end{array}$ & \multirow{2}{*}{$\begin{array}{c}\text { Completed Grade } 12 \text { or } \\
\text { higher }\end{array}$} & 0.97 & 0.352 & 1.07 & 0.378 \\
\hline & $\begin{array}{c}\text { High school (Grade } 8 \text { - } \\
\text { Grade 11) }\end{array}$ & & 0.93 & 0.257 & 0.62 & 0.293 \\
\hline & Sanitation & Flush toilet & 1.11 & 0.426 & 0.68 & 0.487 \\
\hline & Water source & Piped in dwelling & $2.31^{* *}$ & 0.274 & 0.97 & 0.307 \\
\hline & Electricity supply & Yes & 0.74 & 0.582 & 1.43 & 0.652 \\
\hline & Food security & Yes & $2.21^{* *}$ & 0.288 & $2.33^{* *}$ & 0.31 \\
\hline & No travel & \multirow{2}{*}{$\begin{array}{c}\text { Travels for less than } 60 \\
\text { minutes }\end{array}$} & 1.34 & 0.352 & 0.97 & 0.393 \\
\hline & $\begin{array}{c}\text { Travels for more than } 60 \\
\text { minutes }\end{array}$ & & $2.16^{*}$ & 0.325 & 1.14 & 0.375 \\
\hline & Health limitations & No & 0.87 & 0.552 & $3.18^{*}$ & 0.53 \\
\hline$\beta_{4}$ & Acc & & 1.03 & 0.025 & 1.04 & 0.028 \\
\hline$\beta_{5}$ & AccBRT & & 0.86 & 0.098 & 0.88 & 0.112 \\
\hline$\beta_{6}$ & Year•BRT & 2013·Treatment & 1.25 & 0.56 & 1.18 & 0.615 \\
\hline$\beta_{7}$ & PT User•BRT & $\begin{array}{c}\text { Frequent PT } \\
\text { user•Treatment }\end{array}$ & 0.56 & 0.496 & $3.62^{*}$ & 0.55 \\
\hline$\beta_{8}$ & AccBRT•BRT & & 0.94 & 0.219 & 1.25 & 0.221 \\
\hline & & Number of observations & \multicolumn{2}{|c|}{423} & \multicolumn{2}{|c|}{423} \\
\hline & & -2 LogLikelihood & \multicolumn{2}{|c|}{$634.4^{* *}$} & \multicolumn{2}{|c|}{$527.9^{* *}$} \\
\hline & & Goodness of fit: Pearson & \multicolumn{2}{|c|}{0.266} & \multicolumn{2}{|c|}{0.302} \\
\hline \multicolumn{3}{|r|}{ Goodness of fit: Deviance } & \multicolumn{2}{|c|}{1.000} & \multicolumn{2}{|c|}{1.000} \\
\hline \multicolumn{3}{|c|}{ Test of parallel lines significance $\left(X^{2}\right)$} & \multicolumn{2}{|c|}{0.737} & \multicolumn{2}{|c|}{0.143} \\
\hline
\end{tabular}

There was no statistically significant evidence that a respondent's satisfaction with his/her amount of free time was affected by the general time trend from 2009 to 2013 . The predictor variables that did have a statistically significant effect on the variable are food security and 
health limitations, both predictors were used to capture respondent characteristics. $\beta_{7}$ was also statistically significant, suggesting that the odds of: a) a non-frequent PT user in the treatment or control group and b) a frequent PT user in the control group being less satisfied are 3.62 times that of a frequent PT user within close proximity to the BRT. In other words, there is a well-being benefit associated with being a frequent PT user residing within $800 \mathrm{~m}$ of BRT stops and stations (i.e. the served community) in terms of satisfaction with the amount of free time available. The treatment effect $\left(\beta_{6}\right)$ is not statistically significant for either measure of subjective well-being, suggesting that implementation of the BRT did not significantly improve the satisfaction of the served community relative to those further removed from the service. This could be due to the aforementioned shortcomings of the BRT such as the duplication of existing and more robust systems with larger catchment areas serving an already well-served route, as well as the provision of limited accessibility in comparison to the more widespread networks. In addition, it is also consistent with findings of Venter and Vaz (2014) in which they observed the community members' perceptions of the Rea Vaya BRT, particularly in Orlando, Soweto where construction of the BRT was accompanied by upgrades to streets and the general service area of the routes. They found that although the community had positive perceptions of the service, there was no significant indication that proximity to the service improved their overall satisfaction. It was found that satisfaction was primarily driven by other factors such as housing and employment.

Although there is no statistically significant evidence that merely being located within close proximity to the BRT affected these measures of subjective well-being, there appears to be some evidence that those who are more likely to use the service may be more satisfied with the amount of free time they have available. Due to the use of dedicated bus lanes, the Rea Vaya Phase 1A has been tied to improvements in travel time and subsequently an increase in travel time savings for users of the service (Carrigan et al., 2014). Therefore, this suggests that the BRT in Johannesburg is beneficial as a transport project for the served community that is more likely to use the service, but not as a general urban intervention able to improve the life satisfaction of the served community members who do not make use of the service. In the long-run, well-being benefits to the wider community may become evident as modal shifts from private vehicles to the BRT occur, reducing congestion on the roads, as well as through the densification of mixed land-use development and redistribution of opportunities along the trunk and feeder lines, each of which will take longer to manifest.

\section{Conclusions and recommendations}

The Access Envelope Methodology was applied to: a) measure the time-series development of accessibility, using a poverty-relevant metric, over a time period when public transport was expanded through the introduction of the BRT, b) identify and measure the extent to which investment in public transport, particularly BRT, contributed to these changes in the accessibility patterns of the urban poor, and c) attempt to identify wider social benefits, in terms of subjective well-being, of accessibility improvements driven by public transport investment.

The results revealed that in a polycentric region, the highest levels of accessibility are observed for regions within close proximity to all economic nodes, not only the CBD. Therefore, in polycentric regions which grapple with poor modal integration, fixation on 
providing increased accessibility to an already well accessible CBD could be ineffective in terms of significantly improving accessibility to jobs. This notion is supported by the computed accessibility levels after the advent of the Rea Vaya BRT, which revealed that the BRT improved travel time accessibility for Soweto residents to the CBD, but only minimally from 2011 to 2013. The results also revealed the value of decentralization, which allows previously disadvantage groups in the peripheries access to key economic areas without the need for any considerable transport investment, simply by improving the affordability of the existing modes.

The regression model revealed that merely being located near BRT trunk and feeder lines, pre-treatment and post-treatment, did not result in improvements in satisfaction with life as a whole or the amount of free time a respondent had available. There is also no statistically significant evidence that the additional (albeit small) accessibility provided by the BRT to served communities generally improves their sense of well-being. Therefore, there is no discernible "wider benefit" associated with access on its own. This is troubling as it casts doubt on the widespread interpretation of accessibility as a fundamental "good" delivered by transport investments; it is quite challenging to empirically demonstrate this "good".

The results also reveal that those who are more likely to actually use the BRT are better off in terms of the latter measure of well-being (free time), as opposed to those who are unlikely to make use of the service. It appears the subjective well-being benefit of the BRT is associated with actual use of the BRT system, and not simply a spill-over of the intervention to the served community regardless of whether or not they make use of the service. This suggests that BRT in Johannesburg is beneficial as a transport project, but not as a general urban intervention able to improve the overall amenity of served communities. This is consistent with findings in Bogotá and Santiago de Cali in Colombia, in which the BRT transport-related advances did not translate to social and/or mobility benefits or improvements (Jaramillo et al., 2012; Combs, 2017). Perhaps more effort related to land use, property value, and urban design changes in areas served by the BRT is required to leverage non-user benefits, however, this can only manifest over a longer time-period.

Further work is required to refine the computation of the accessibility measure and summary measures for a time-series analysis. Some suggestions include adjusting what is deemed the reasonable NWAC from one analysis year to the next and imposing a stricter penalty on walking trips. In addition, a sensitivity analysis of the access envelope technique input data would reveal the response of the access measure to the various input parameters. The methodology should be further calibrated to validate its use as a transport and land-use planning tool. With regards to the regression model, the robustness of the findings needs to be tested using a sensitivity analysis to determine the effect of various selection methods of treatment and control group observations. The regression analysis may also be repeated using alternative accessibility metrics and/or specifications of well-being might also be tested if the data permits.

\section{Acknowledgements}

The work of Willem Badenhorst and Johan du Toit from Mapable in assisting with software development is greatly appreciated. The data used in this paper is taken from the Quality of

Page 23 of 27 
Life survey commissioned by the Gauteng City-Region Observatory, a partnership of the University of Johannesburg, the University of the Witwatersrand, and the Gauteng Provincial Government. Preparation of the paper was partly sponsored by the Volvo Education and Research Foundation via the BRT+ Centre of Excellence.

\section{References}

Axhausen, K. (2008). Accessibility: Long-term perspectives. Journal of Transport and Land Use, 1(2), pp. 5-22.

Blackford, J.U. (2009). Propensity Scores: Method for Matching on Multiple Variables in Down Syndrome Research. Intellectual and Developmental Disabilities: October 2009, Vol. 47, No. 5, pp. 348-357.

Bocarejo S., J.P. and Oviedo H., D.R. (2012). Transport accessibility and social inequities: a tool for identification of mobility needs and evaluation of transport investments. Journal of Transport Geography, 12, pp. 142 - 154.

Bocajero, J.P.; Portilla, I.; Pérez, M.A. (2013). Impact of Transmilenio on density, land use, and land value in Bogotá. Research in Transport Economics, 40, pp. 78 - 86.

Carrigan, A., King, R., Velasquez, J. M., Raifman, M., \& Duduta, N. (2014). Social, Environmental and Economic Impacts of BRT Systems: Bus rapid transit case studies from around the world. ().EMBARQ.

Cervero, R. (2005). Accessible cities and regions: A framework for sustainable transport and urbanism in the 21st century. (). California: UC Berkeley Center for Future Urban Transport: A Volvo Center of Excellence.

Cheng, J. and Bertolini, L. (2013). Measuring urban job accessibility with distance decay, competition and diversity. Journal of Transport Geography, 30, pp. 100-109.

CoJ. (2013). Strategic integrated transport plan framework for the city of Joburg. (). Johannesburg: CoJ.

Combs, T. (2017). Examining changes in travel patterns among the lower wealth households after BRT investments in Bogotá, Colombia. Journal of Transport Geography, 60, 11-20.

Condeço-Melhorado, A., Zofío, J.L. and Christidis, P. (2017). Drivers of changes in Spanish accessibility for the 1960-2010 period. European Transport Research Review, 9(2), pp. 19.

CSIR. (2000). Chapter 5.2: Public Transport. Guidelines for human settlement planning and design. Pretoria: CSIR Buidling and Construction Technology. 1-22.

Dalvi, M.Q. and Martin, K.M. (1976). The measurement of accessibility: Some preliminary results. Transportation, 5(1), pp. 17-42.

Delamater, P., Messina, J., Shortridge, A., \& Grady, S. (2012). Measuring geographic access to health care: Raster and network-based methods. International Journal of Health Geographics, 11(15)

Delbosc, A. (2012). The role of well-being in transport policy. Transport Policy, 23: 25-33.

Delbosc, A., \& Currie, G. (2011). The spatial context of transport disadvantage, social exclusion and well-being. Journal of Transport Geography, 19, 1130-1137. 
Diener, E., Lucas, R., Schimmack, U., Helliwell, J. (2009). Well-being for public policy. Oxford Scholarship Online. http://dx.doi.org/10.1093/acprof:oso/ 9780195334074.001.0001.

El-Geneidy, A. and Levinson, D. (2006). Mapping accessibility over time. Journal of Maps, , pp. 76-87.

Everatt, D. (2017). Quality of Life in the Gauteng City-Region, South Africa. Social Indicators Research, 130(1), pp. 71-86.

Falavigna, C. and Hernandez, D. (2016). Assessing inequalities on public transport affordability in two latin American cities: Montevideo (Uruguay) and Córdoba (Argentina). Transport Policy, 35, pp. 145 - 155.

Ford, A., Barr, S., Dawson, R., \& James, P. (2015). Transport accessibility analysis using GIS: Assessing sustainable transport in London. ISPRS International Journal of GeoInformation, 4, 124-149.

Foth, N., Manaugh, K. and El-Geneidy, A.M. (2013). Towards equitable transit: Examining transit accessibility and social need in Toronto, Canada, 1996-2006. Journal of Transport Geography, 29, pp. 1-10.

Geurs, K. T., \& van Wee, B. (2004). Accessibility evaluation of land-use and transport strategies: Review and research directions. Journal of Transport Geography, 12(2), 127-140. doi:10.1016/j.jtrangeo.2003.10.005

Gotz, G., Wray, C., Venter, C., Badenhorst, W., Trangoš, G., \& Culwick, C. (2014). Mobility in the Gauteng city-region. (). Johannesburg: GCRO.

GPG. (2012). Gauteng 2055: A discussion document on the long-term development plan for the Gauteng city-region. Johannesburg: GPG.

Grengs, J., (2010). Job acessibility and the modal mismatch in Detroit. Journal of Transport Geography, 18, 42-54.

Greyling, T. (2013). A composite index of quality of life for the Gauteng city-region: a principal component analysis approach. Johannesburg: Gauteng City Region Observatory.

Guzman, L.A., Oviedo, D. and Rivera, C. (2017). Assessing equity in transport accessibility to work and study: The Bogotá region.Journal of Transport Geography, 58, pp. 236 - 246.

Hansen, W.G. (1959). How Accessibility Shapes Land Use. Journal of the American Planning Association, 25(2), pp. 73-76.

lacono, M., Krizek, K.J. and El-Geneidy, A. (2010). Measuring non-motorized accessibility: issues, alternatives, and execution. Journal of Transport Geography, 18(1), pp. 133-140. Jaramillo, C., Lizárraga, C., \& Grindlay, A. L. (2012). Spatial disparity in transport social needs and public transport provision in Santiago de Cali (Colombia) doi:http://dx.doi.org/10.1016/j.jtrangeo.2012.04.014

Kenyon, S. (2003). Understanding social exclusion and social inclusion. Proceedings of the Institution of Civil Engineers: Municipal Engineer, 156(2), 97-104. doi:10.1680/muen.156.2.97.37665

Kenyon, S. (2011). Transport and social exclusion: access to higher education in the UK policy context. Journal of Transport Geography, 19(4), pp. 763-771. 
Kenyon, S., Lyons, G., \& Rafferty, J. (2002). Transport and social exclusion: Investigating the possibility of promoting inclusion through virtual mobility. Journal of Transport Geography, 10(3), 207-219.

Kett, M. and Deluca, M. (2016). Transport and Access to Inclusive Education in Mashonaland West Province, Zimbabwe. Social Inclusion, 4(3), pp. 61-71.

Koopmans, C., Groot, W., Warffemius, P., Annema, J.A. and Hoogendoorn-Lanser, S. (2013). Measuring generalised transport costs as an indicator of accessibility changes over time. Transport Policy, 29, pp. 154 - 159.

Lechner, M. (2010). The Estimation of Causal Effects by Difference-in-Difference Methods. Foundations and Trends in Econometrics, 4(3), pp. 165-224.

López, E. (2007). Assessment of Transport Infrastructure Plans: a strategic approach integrating environmental, efficiency and cohesion aspects., Universidad Politécnica de Madrid.

Lui, X. and Koirala, H. (2012). Ordinal Regression Analysis: Using Genrealized Ordinal Logistic Regression Models to Estimate Educational Data. Journal of Modern Applied Satistical Methods, 11(1), 242-254.

Martens, K. (2017). Transport Justice. 1 edn. New York: Routledge.

Martin, J.C. and Van Wee, B. (2011). Guest Editorial: What Can We Learn from Accessibility Modelling? ETJIR, 11(4), pp. 346-349.

Miller, H., \& Wu, Y. (2000). GIS software for measuring space-time accessibility in transportation planning and analysis. Geolnformatica, 4(2), 141-159.

Mokonyama, M. and Mubiwa, B. (2014). Transport in the shaping of space. In: P. Harrison, G. Gotz, A. Todes and C. Wray, eds, Changing Space, Changing City: Johannesburg After Apartheid. 1 edn. Johannesburg, South Africa: Wits University Press, pp. 194-214.

Morris, J.M., Dumble, P.L. and Wigan, M.R. (1979). Accessibility indicators for transport planning. Transportation Research Part A: General, 13(2), pp. 91-109.

Mushongera, D., Zikhali, P., \& Ngwenya, P. (2015). A multidimensional poverty index for Gauteng province, South Africa: Evidence from quality of life survey data. Social Indicators Research, , 1-27.

Noble, A. and Bickford, G. (2013). City of Johannesburg Public Transport Record: Summary of data Draft 2. Johannesburg: ARUP.

OECD. (2011). OECD Territorial Reviews: The Gauteng City-Region, South Africa 2011, OECD Publishing.http://dx.doi.org/10.1787/9789264122840-en.

Preston, J., \& Rajé, F. (2007). Accessibility, mobility and transport-related social exclusion. Journal of Transport Geography, 15(3), 151-160. doi:http://dx.doi.org/10.1016/j.jtrangeo.2006.05.002

Rodriguez, C., Peralta-Quirós, T., Guzman, L.A., Reyes, S.A.C. (2017). Accessibility, affordability, and addressing informal services in bus reform. Transportation Research Record, 2634, pp. 35-42. doi: https://doi-org.uplib.idm.oclc.org/10.3141/2634-06.

STATSSA. (2014). Poverty Trends in South Africa: An examination of absolute poverty between 2006 and 2011. Statistics South Africa. 
Titheridge, H.; Christie, N.; Mackett, R.; Hernández, D.O.; Ye, R. (2014). Transport and Poverty. A Review of the Evidence. UCL, London, UK.

Todes, A. (2012). Urban growth and strategic spatial planning in Johannesburg, South Africa. Elsevier, (29), 158-165.

van Dijk, J., Krygsman, S., de Jong, T. (2015). Toward spatial justice: The spatial equity effects of a toll road in Cape Town, South Africa. Journal of Transport and Land Use, 8(3), pp. 95-114

Van Wee, B., Hagoort, M., Annema, J.A. (2001). Accessibility measures with competition. Journal of Transport Geography, 9(3), pp. 199-208

Venter, C., and Cross, C. (2014). Access envelopes: A new accessibility mapping technique for transport and settlements planning. Ssb/Trp/Mdm, (64), 43-52.

Venter, C. and Vaz, E. (2014). Transformation through transportation: Some early impacts of Bus Rapid Transit in Orlando, Soweto. In: P. Harrison, G. Gotz, A. Todes and C. Wray, eds, Changing Space, Changing City: Johannesburg After Apartheid. 1 edn. Johannesburg, South Africa: Wits University Press, pp. 443-455.

Venter, C., Jennings, G., Hidalgo, D. and Pineda, A.F.V. (2018). The equity impacts of bus rapid transit: a review of the evidence and implications for sustainable transport. International Journal of Sustainable Transportation, 12(2), pp. 140 - 152.

doi:https://10.1080/15568318.2017.1340528.

Venter, C.J., Mohammed, S.O. (2013). Estimating car ownership and transport energy consumption: A disaggregate study in Nelson Mandela Bay. Journal of the South African Institution of Civil Engineering, 55(1), pp. 2-10

Venter, C. (2011). Transport expenditure and affordability: The cost of being mobile. Development Southern Africa, 28(1), pp. 121-140.

Venter, C. (2016). Assessing the potential of bus rapid transit-led network restructuring for enhancing affordable access to employment -the case of Johannesburg's corridors of freedom. Research in Transportation Economics, 59, 441-449.

William, M. K. (2006). The regression-discontinuity design. Retrieved from http://socialresearchmethods.net/kb/quasird.htm 